\title{
A New Optimization Approach for Maximizing the Photovoltaic Panel Power Based on Genetic Algorithm and Lagrange Multiplier Algorithm
}

\author{
Mahdi M. M. El-Arini, Ahmed M. Othman, and Ahmed Fathy \\ Electrical Power and Machine Department, Faculty of Engineering, Zagazig University, Zagazig 44519, Egypt \\ Correspondence should be addressed to Ahmed Fathy; ahmed_fathy_1984@yahoo.com
}

Received 27 October 2012; Revised 26 January 2013; Accepted 13 February 2013

Academic Editor: Peter Rupnowski

Copyright ( 2013 Mahdi M. M. El-Arini et al. This is an open access article distributed under the Creative Commons Attribution License, which permits unrestricted use, distribution, and reproduction in any medium, provided the original work is properly cited.

\begin{abstract}
In recent years, the solar energy has become one of the most important alternative sources of electric energy, so it is important to operate photovoltaic (PV) panel at the optimal point to obtain the possible maximum efficiency. This paper presents a new optimization approach to maximize the electrical power of a PV panel. The technique which is based on objective function represents the output power of the PV panel and constraints, equality and inequality. First the dummy variables that have effect on the output power are classified into two categories: dependent and independent. The proposed approach is a multistage one as the genetic algorithm, GA, is used to obtain the best initial population at optimal solution and this initial population is fed to Lagrange multiplier algorithm (LM), then a comparison between the two algorithms, GA and LM, is performed. The proposed technique is applied to solar radiation measured at Helwan city at latitude $29.87^{\circ}$, Egypt. The results showed that the proposed technique is applicable.
\end{abstract}

\section{Introduction}

In the last years, global warming and energy policies have become a hot topic on the international agenda as the developed countries are trying to reduce their greenhouse gas emissions. Renewable energy sources are considered as a technological option for generating clean energy. Among them, photovoltaic $(\mathrm{PV})$ system has received a great attention as it appears to be one of the most promising renewable energy sources. PV power generation has an important role to play as it is a green source. The only emissions associated with PV power generation are those from the production of its components. However, the development for improving the efficiency of the PV system is still a challenging field of research. Maximum power point tracking (MPPT) algorithms are necessary in PV applications because the MPP of a solar module varies with the irradiation and temperature as shown in Figures 1 and 2. So, the use of MPPT is required to obtain the maximum output power from a module [1]. The optimization process can be defined as the finding values of variables that minimize or maximize the objective function and satisfy the constraints. The optimization problems are centered on three main factors which are as follows:

(1) objective function which is to be minimized or maximized;

(2) a set of unknown variables that have effect on the objective function;

(3) A set of constraints that allow the unknown to take on certain values but exclude others.

The most popular literature optimization techniques of the PV power are based on the usage of the MPPT. The MPPT control method uses one estimate processes between every two Perturb processes in search for the maximum PV output (EPP) which is proposed in [2].

An intelligent approach for MPPT DC-DC Boost converter focused on Perturb and Observe ( $\mathrm{P} \& \mathrm{O})$ algorithm and compared to a designed fuzzy logic controller which is presented in [3]. A comparative study of two types of MPPT which are $\mathrm{P} \& \mathrm{O}$ and incremental conductance method is introduced in [4]. The implementation of fuzzy logic 


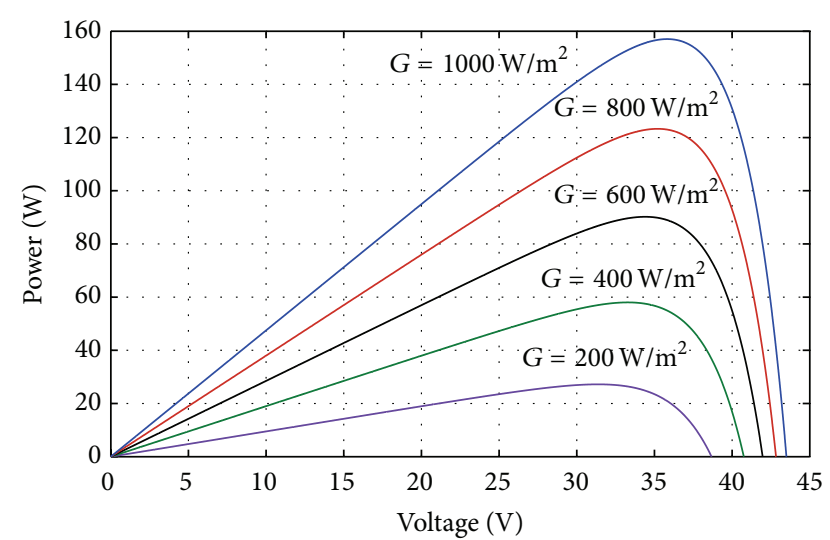

FIGURE 1: PV module voltage-power at different irradiance levels.

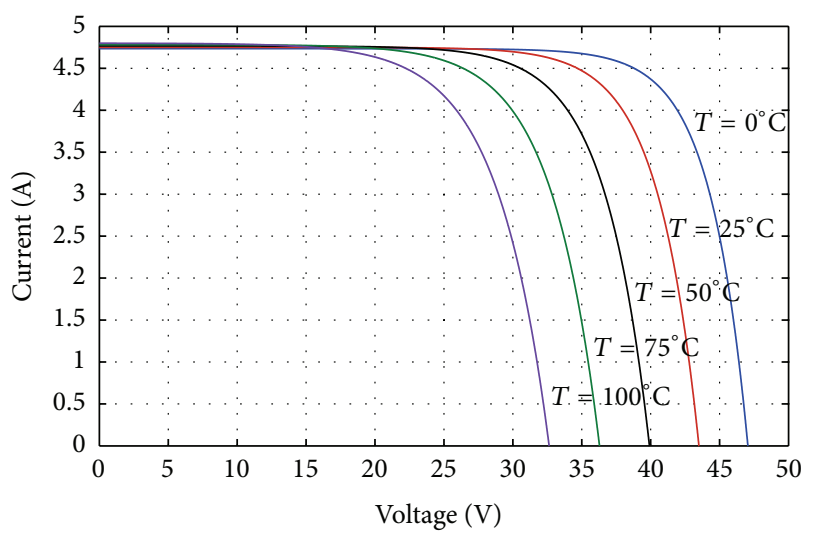

FIGURE 2: PV module voltage-current at different temperature levels.

controller based on the change of the PV module power, $\Delta P_{\mathrm{pv}}$, and its change with respect to the module voltage, $\Delta P_{\mathrm{pv}} / \Delta V$ is studied in [5], the proposed fuzzy logic determines the size of the voltage then obtains the corresponding Power. The performance of fuzzy logic with various membership functions (MFs) is tested to optimize the MPPT. A novel intelligent fuzzy logic controller for MPPT based on boost converter and single-phase grid-connected inverter is introduced in [6]. An intelligent control method for MPPT of a photovoltaic system under variable temperature and insolation conditions which uses a fuzzy logic controller applied to a DC-DC converter device is proposed in [7]. A fuzzy logic control to control MPPT for a PV system is proposed in [8]. The analysis of the optimal operation of PV panels as a function of the weather conditions (solar irradiation, temperatures), and the design of a PV system provided with MPPT command ensuring instantaneously optimal operation of photovoltaic panels is presented in [9]. MPPT simulation based on using particle swarm optimization (PSO) algorithm is presented in [10]. The algorithm is employed on a buck-boost converter and tested experimentally using a PV array simulator. The design and implementation of an optimized stand-alone solar pumping system are presented in [11].

This paper presents a new optimization approach to maximize the electrical power of the PV panel. The technique

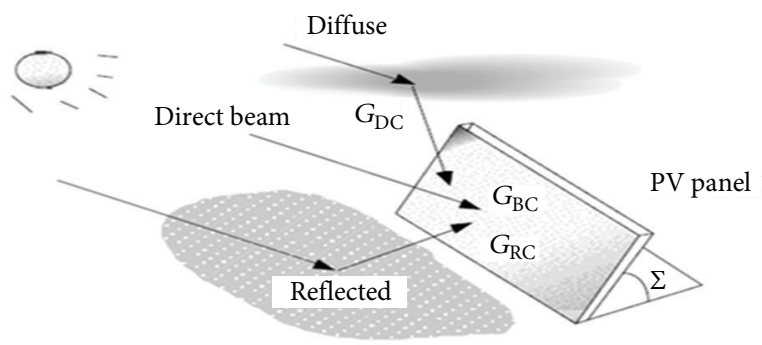

FIgure 3: Direct, diffuse, and reflected beams that strike the PV panel.

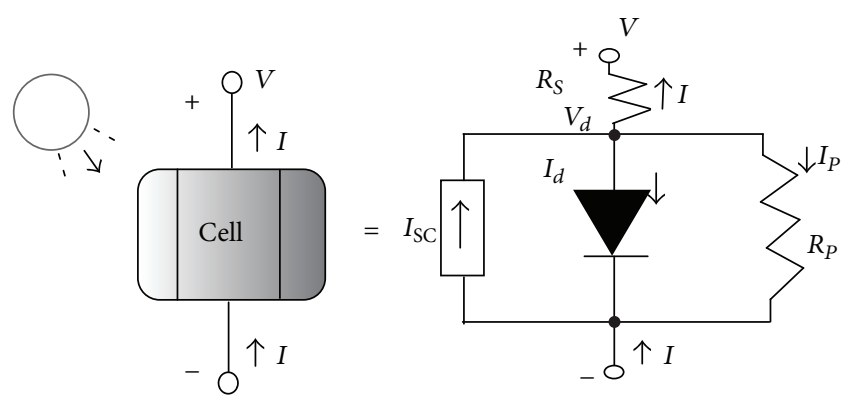

FIgURE 4: The equivalent circuit for a PV cell.

which is based on objective function represents the output power of the PV module and constraints, equality and inequality. First, the dummy variables that have effect on the output power are classified into two categories: dependent and independent. The proposed approach is a multistage one as GA is used to obtain the best initial population at optimal solution, and then the best initial population is fed to Lagrange multiplier algorithm (LM), then a comparison between two algorithms, GA and LM, is performed. The proposed technique is applied to solar radiation measured at Helwan city at latitude $29.87^{\circ}$, Egypt. The results showed that the proposed technique is applicable.

\section{Mathematical Model of PV Module}

The solar flux striking a PV panel can be resolved to three components; direct beam radiation that passes in a straight line through the atmosphere to the receiver, diffuse radiation that has been scattered by molecules in the atmosphere, and reflected radiation that has bounced off the ground or other surface in front of the collector as shown in Figure 3.

The total rate of radiation $G_{C}$ strikes a collector on a clear day as follows [12]:

$$
\begin{gathered}
G_{\mathrm{C}}=G_{\mathrm{BC}}+G_{\mathrm{DC}}+G_{\mathrm{RC}}, \\
G_{C}=A e^{-k m}\left[\cos \beta \cos \left(\varphi_{\mathrm{S}}-\varphi_{\mathrm{C}}\right) \sin \Sigma+\sin \beta \cos \Sigma\right. \\
\left.+C\left(\frac{1+\cos \Sigma}{2}\right)+\rho(\sin \beta+C)\left(\frac{1-\cos \Sigma}{2}\right)\right], \\
m=\frac{h_{2}}{h_{1}}=\frac{1}{\sin \beta},
\end{gathered}
$$




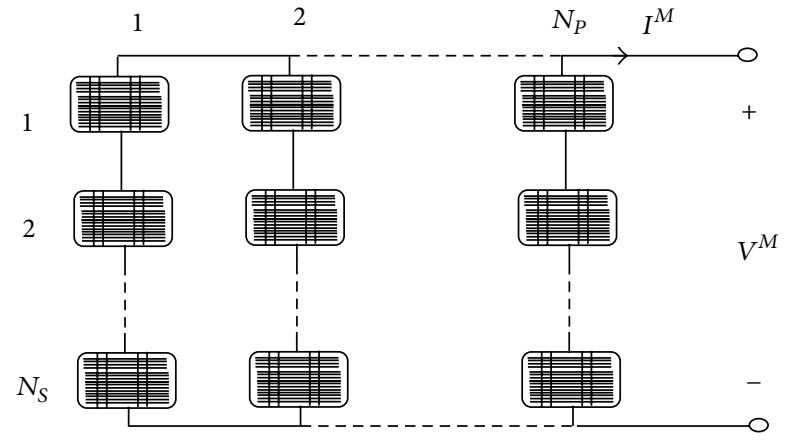

FIgURE 5: The equivalent circuit for a PV module.

where $M$ is the air mass, $\beta$ is the altitude angle, $\varphi_{S}$ is the solar azimuth angle, $\varphi_{C}$ is the $\mathrm{PV}$ module azimuth angle, positive for eastsouth and negative for westsouth, $\Sigma$ is the PV module tilt angle, $\rho$ is reflection factor, and $C$ is sky diffuse factor and is given by the following equation [12]:

$$
C=0.095+0.04 \sin \left[\frac{360}{365}(d-100)\right],
$$

where $A$ and $k$ are dependent on the day number and can be obtained by the following equations [1] and $d$ is the day number:

$$
\begin{gathered}
A=1160+75 \sin \left[\frac{360}{365}(d-275)\right]\left(\mathrm{W} / \mathrm{m}^{2}\right), \\
\quad k=0.174+0.035 \sin \left[\frac{360}{365}(d-100)\right] .
\end{gathered}
$$

A PV cell can be simulated by a real diode in parallel with an ideal current source, $I_{\mathrm{SC}}$, which depends on striking radiation. The generalized equivalent circuit of the PV cell is given in Figure 4 [13, 14].

One can derive the following equations for current and voltage:

$$
\begin{gathered}
I_{\mathrm{SC}}=I+I_{d}+I_{P}, \\
I=I_{\mathrm{SC}}-I_{0}\left\{\exp \left[\frac{q\left(V^{C}+I \cdot R_{s}^{C}\right.}{n k_{b} T_{C}}\right]-1\right\}-\left(\frac{V^{C}+I \cdot R_{s}^{C}}{R_{P}^{C}}\right), \\
I_{0}=\frac{I_{\mathrm{SC}}}{\left(e^{q V / n k_{b} T_{C}}-1\right)} .
\end{gathered}
$$

The reverse saturation current, $I_{0}$, is dependent on the temperature and is given by the following equation:

$$
I_{0}\left(T_{C}\right)=I_{0}\left(T_{\text {ref }}\right) *\left(\frac{T_{C}}{T_{\text {ref }}}\right)^{3} * \exp \left(\frac{q E_{G}}{n K}\left(\frac{1}{T_{\text {ref }}}-\frac{1}{T_{C}}\right)\right) .
$$

The short circuit current, $I_{\mathrm{SC}}$, depends on the solar radiation and cell temperature as follows:

$$
I_{\mathrm{SC}}=\left[I_{\mathrm{SCr}}+K_{i}\left(T_{\mathrm{C}}-T_{\mathrm{ref}}\right)\right] * G_{\mathrm{C}},
$$

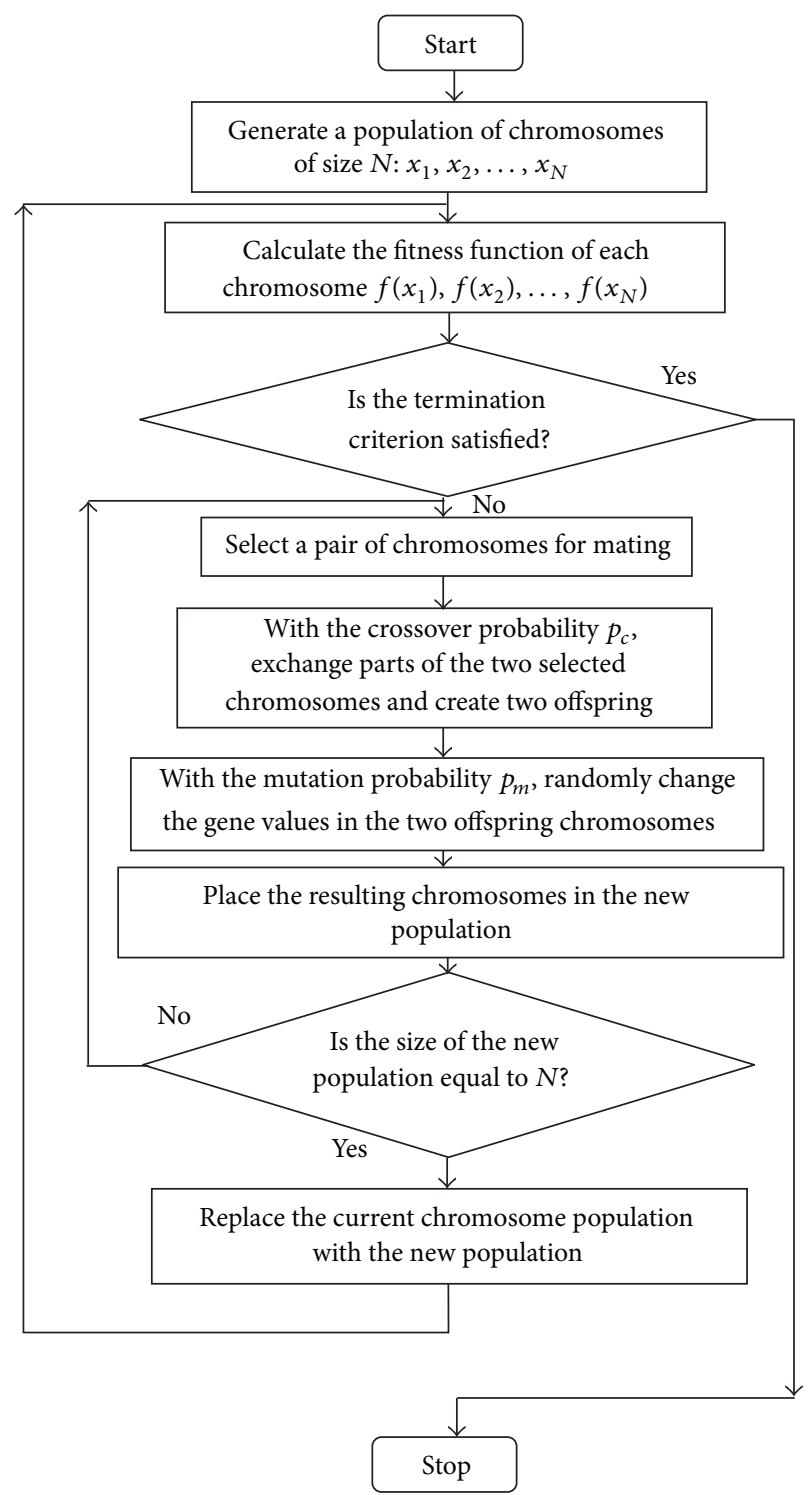

Figure 6: A simple GA flow chart.

where $I$ is the cell output current, $V$ is the cell output voltage, and $R_{S}$ is the cell series resistance $(\Omega)$.

$R_{P}$ is the cell parallel resistance $(\Omega), n$ is the diode ideality factor, $k_{b}$ is the Boltzmann constant $\left(1.38 \mathrm{e}^{-23} \mathrm{~J} / \mathrm{K}\right), T_{C}$ is the cell temperature $\left({ }^{\circ} \mathrm{C}\right), T_{\text {ref }}$ is the reference temperature of the PV cell, $I_{0}\left(T_{\text {ref }}\right)$ is the cell reverse saturation current at reference temperature, $E_{G}$ is the band gap of semiconductor used in the cell, $I_{\mathrm{SCr}}$ is the cell short circuit current at reference temperature and radiation, $K_{i}$ is the short circuit current temperature coefficient, and $G_{C}$ is the solar radiation strikes a tilted module in $\mathrm{W} / \mathrm{m}^{2}$.

The cell temperature is calculated as follows:

$$
T_{C}=T_{\text {ambient }}+\left(\frac{\text { NOCT }-20^{\circ}}{0.8}\right) * G_{C},
$$

where $T_{\text {ambient }}$ is ambient temperature and NOCT is cell temperature in a module when ambient is $20^{\circ} \mathrm{C}$. 


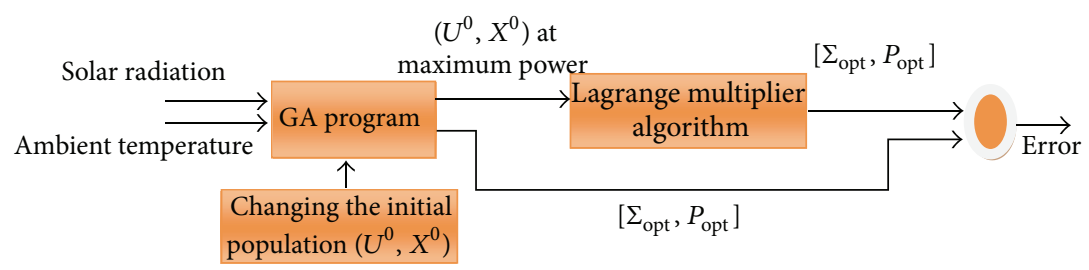

FIGURE 7: The proposed analysis steps.

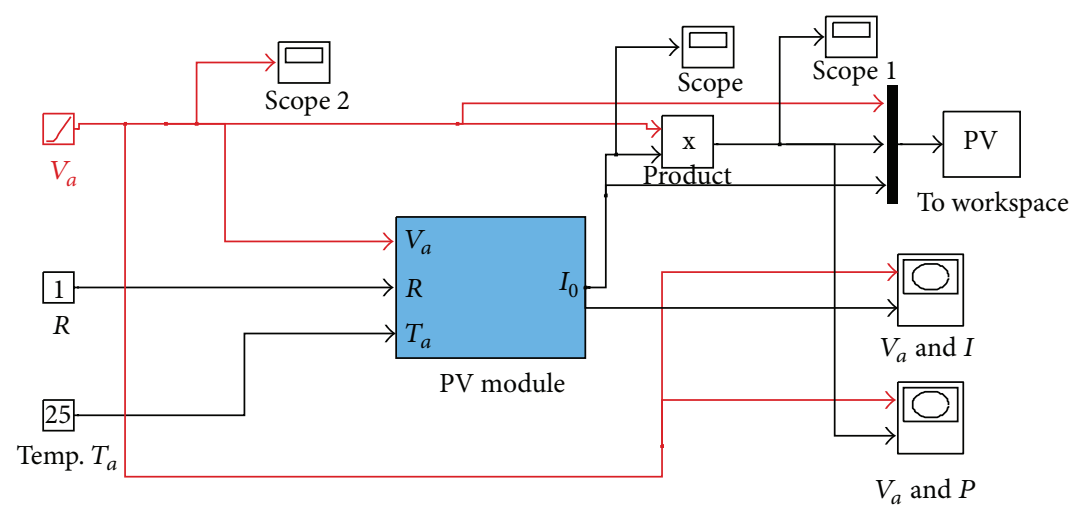

FIGURE 8: Simulink model of the PV module.

A PV module consists of series cells, $N_{S}$, and parallel branches, $N_{P}$, which are given in Figure 5.

The PV module's current $I^{M}$ under variable operating conditions can be described as follows [15]:

$$
\begin{gathered}
I^{M}=N_{p} I_{\mathrm{SC}}-N_{p} I_{0}\left\{\exp \left[\frac{q\left(V^{M} / N_{S}+I^{M} \cdot R_{S}^{M}\right)}{n k_{b} T}\right]-1\right\} \\
\quad-\left(\frac{V^{M} / N_{S}+I^{M} \cdot R_{S}^{M}}{R_{P}^{M}}\right), \\
R_{s}^{M}=\frac{N_{S}}{N_{p}} R_{s}, \quad R_{P}^{M}=\frac{N_{p}}{N_{S}} R_{P}, \quad V^{M}=N_{S} V .
\end{gathered}
$$

\section{Proposed Technique}

3.1. The Proposed Optimization Problem. The mathematical model of any continuous optimization problem can be described as follows:

$$
\text { minimize or maximize } f(X, U) \text {, }
$$

where $f(X, U)$ is an objective function to be minimized or maximized subjected to equality and inequality constraints as follows:

(1) equality constraint

$$
q_{i}(X, U)=0, \quad i=1,2, \ldots, l,
$$

TABLE 1: Electrical characteristic of bpsx150 PV module.

\begin{tabular}{lc}
\hline Maximum power $\left(P_{\max }\right)$ & $150 \mathrm{~W}$ \\
Voltage at $P_{\max }\left(V_{P_{\max }}\right)$ & $34.5 \mathrm{~V}$ \\
Current at $P_{\max }\left(I_{P_{\max }}\right)$ & $4.35 \mathrm{~A}$ \\
Warranted minimum $P_{\max }$ & $140 \mathrm{~W}$ \\
Short-circuit current $\left(I_{\mathrm{sc}}\right)$ & $4.75 \mathrm{~A}$ \\
Open-circuit voltage $\left(V_{\mathrm{oc}}\right)$ & $43.5 \mathrm{~V}$ \\
Maximum system voltage & $600 \mathrm{~V}$ \\
Temperature coefficient of $I_{\mathrm{sc}}$ & $(0.065 \pm 0.015) \% /{ }^{\circ} \mathrm{C}$ \\
Temperature coefficient of $V_{\mathrm{oc}}$ & $-(160 \pm 20) \mathrm{mV} /{ }^{\circ} \mathrm{C}$ \\
Temperature coefficient of power & $-(0.5 \pm 0.05) \% /{ }^{\circ} \mathrm{C}$ \\
NOCT & $47 \pm 2{ }^{\circ} \mathrm{C}$ \\
\hline
\end{tabular}

(2) parametric inequality constraint

$$
\begin{gathered}
X_{j}^{\min } \leq X_{j} \leq X_{j}^{\max }, \quad j=1,2, \ldots, f, \\
U_{k}^{\min } \leq U_{k} \leq U_{k}^{\max }, \quad k=1,2, \ldots, r,
\end{gathered}
$$

(3) functional inequality constraint

$$
h_{y}(X, U) \leq 0, \quad y=1,2, \ldots, p
$$

where $X$ is a vector of state, dependant, variables and $U$ is a vector of control (independent) variables. First the dummy variables that have effect on the PV module power are classified into two categories: independent $(U)$ and dependent variables $(X)-U=\left[N_{S}, N_{P}, d, \Sigma, \varphi_{C}\right]$ and $X=$ $\left[\beta, m, \varphi_{S}, G_{C}, I_{S C}, I_{0}, T_{C}\right]$. 


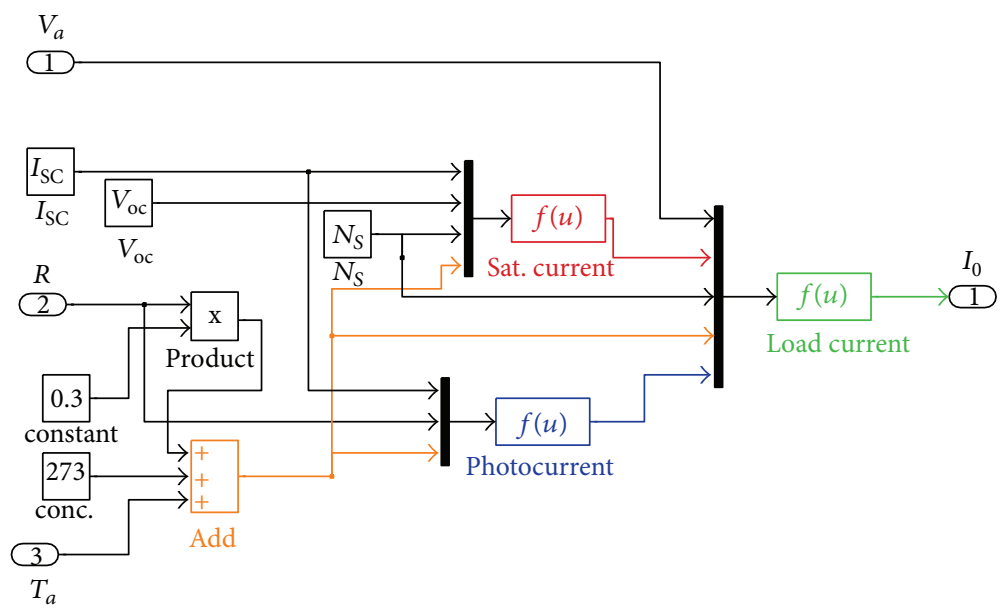

FIgURE 9: Detailed configuration of PV module subsystem.

The proposed objective function is expressed in the following form:

$$
\begin{gathered}
\operatorname{maximize} \quad P_{\mathrm{pv}}(X, U) \\
=f\left(T_{C}, V^{M}, m, \Sigma, \varphi_{C}, \beta, L, \omega, G_{C}, I_{0}\right) \\
=\left(N_{s} V^{C}\right) * I_{n+1}^{M} \\
=V^{M} *\left(I _ { n } ^ { M } * \left(1-\left(1 \left(1+\psi\left(T_{C}\right)\right.\right.\right.\right. \\
*\left(1-\mu\left(V^{M}, T_{C}, I^{M}\right)\right) \\
\left.\left.\left.* \partial\left(T_{C}\right)\right)^{-1}\right)\right) \\
+\left(\left(\psi\left(T_{C}\right) * \epsilon\left(m, \varphi_{S}, \beta, \Sigma, \varphi_{C}\right)\right.\right. \\
\left.* \mu\left(V^{M}, T_{C}, I^{M}\right)+\gamma\left(V^{M}\right)\right) \\
\times\left(1+\psi\left(T_{C}\right) *\left(1-\mu\left(V^{M}, T_{C}, I^{M}\right)\right)\right. \\
\left.\left.\left.* \partial\left(T_{C}\right)\right)^{-1}\right)\right) .
\end{gathered}
$$

Subjected to the following proposed parametric constrained:

$$
\begin{gathered}
N_{S}^{\min }<N_{S}<N_{S}^{\max }, \\
N_{P}^{\min }<N_{P}<N_{P}^{\max }, \\
d^{\min }<d<d^{\max } \longrightarrow 1 \leq d \leq 365, \\
\Sigma^{\min }<\Sigma<\Sigma^{\max } \longrightarrow 0 \leq \Sigma \leq 80, \\
\varphi_{C}^{\min }<\varphi_{C}<\varphi_{C}^{\max } \longrightarrow-45 \leq \varphi_{C} \leq 45,
\end{gathered}
$$

the proposed equality constraint is given as

$$
g(U, X)=V_{\text {oc }}-184.0293 * \frac{N_{s} V^{C}}{T}=0 .
$$

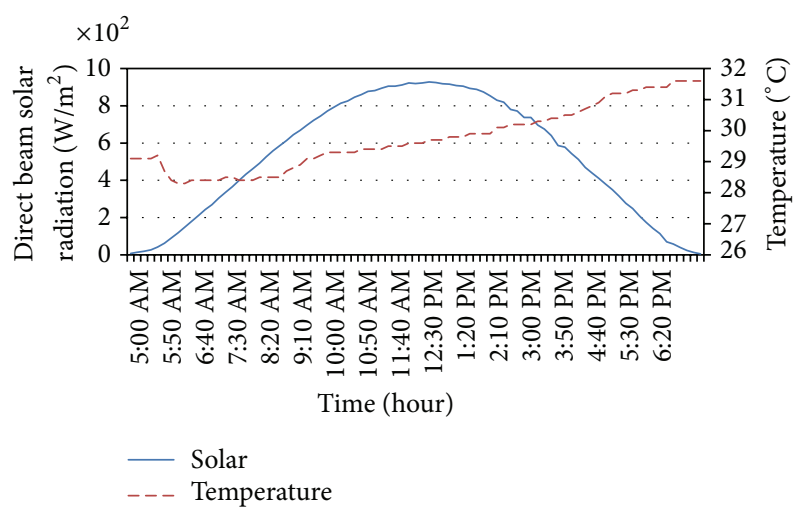

FIGURE 10: Direct beam solar radiation and ambient temperature for Helwan city, Egypt.
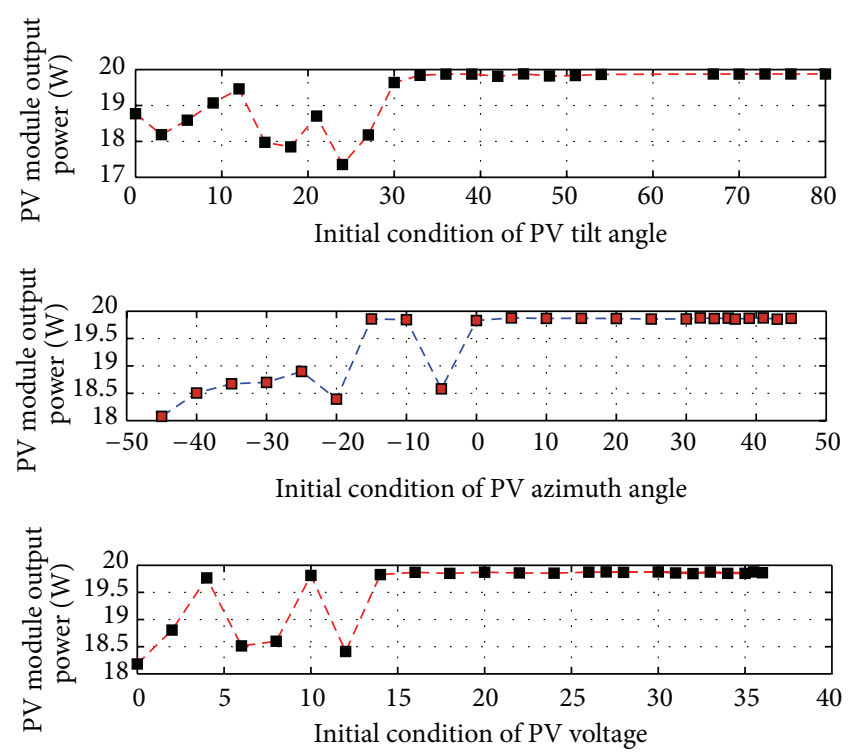

FigURE 11: The optimal PV module power at changing the initial population in GA at 6:10 AM. 


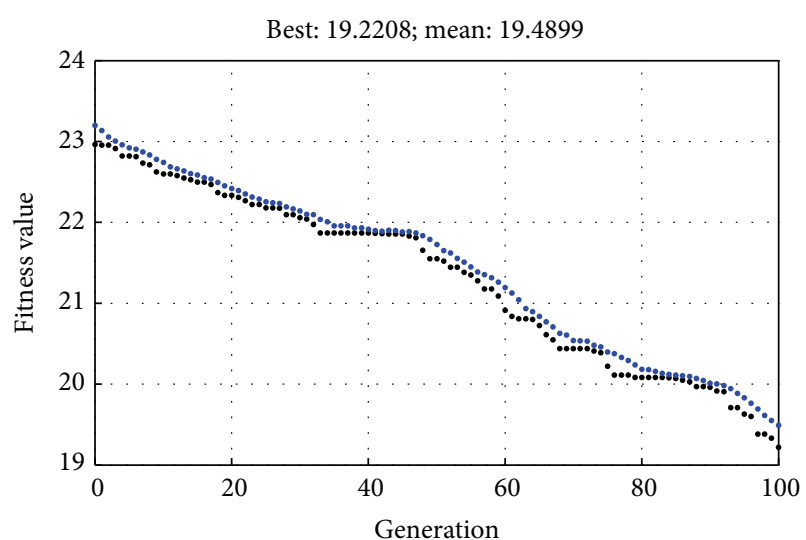

- Best fitness

- Mean fitness

(a)

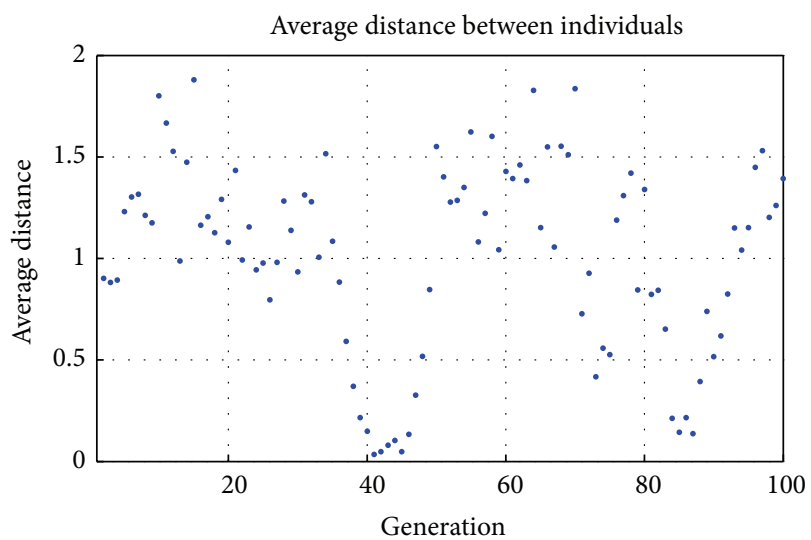

(c)

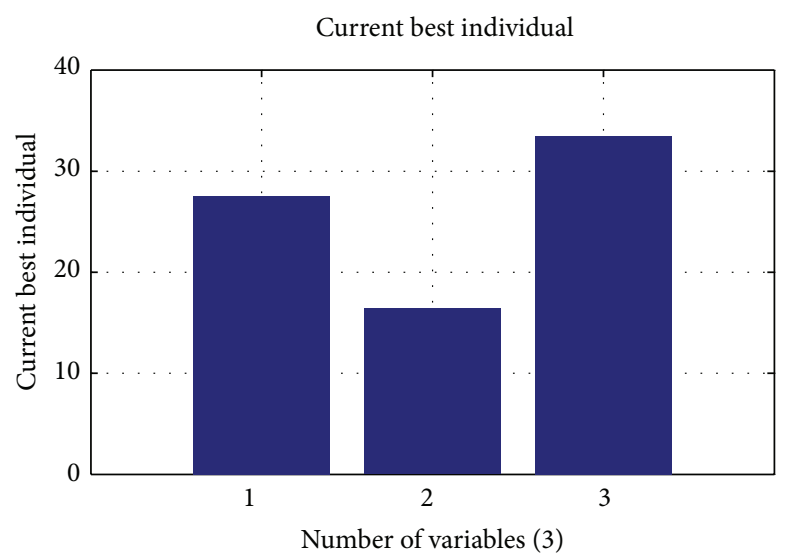

(b)

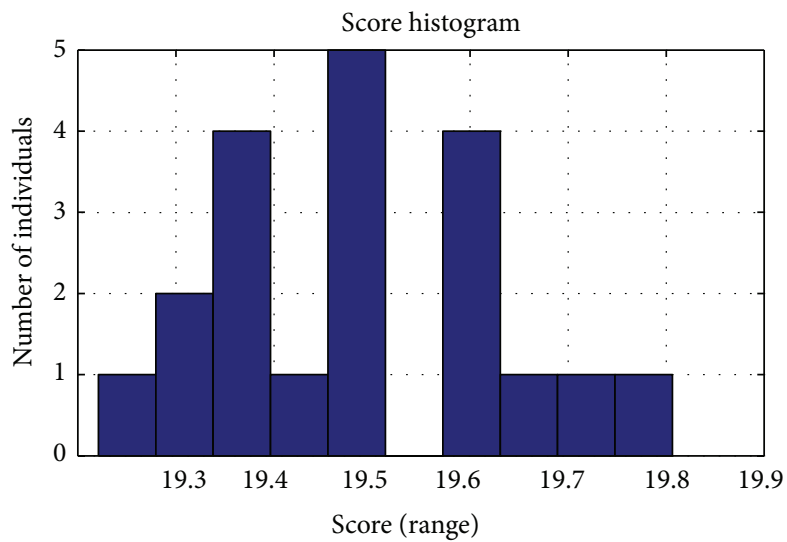

(d)

FIgURE 12: The optimal PV module power at changing the initial population in GA at 6:10 AM.

The limits of independent variables are selected according to the following aspects.

(1) When $\Sigma=0^{\circ}$, the PV module becomes horizontal and produces power, while for $\Sigma=90$, the PV module becomes vertical and produces zero power; so, the selected limits are assumed between $0^{\circ}$ and $80^{\circ}$.

(2) The PV module azimuth angle is positive for east of south and becomes negative for west of south; so, the limits are selected as $\pm 45^{\circ}$.

3.2. Genetic Algorithm. Genetic algorithm, GA, is gradient free, parallel optimization algorithms that use a performance criterion for evaluation and a population of possible solutions to the search for a global optimum. GA is capable of handling complex and irregular solution spaces and has been applied to various difficult optimization problems [16]. It is inspired by the biological process of Darwinian evolution where selection, mutation, and crossover play a major role. The manipulation is done by the genetic operators that work on the chromosomes in which the parameters of possible solutions are encoded. In each generation of the GA, the new solutions

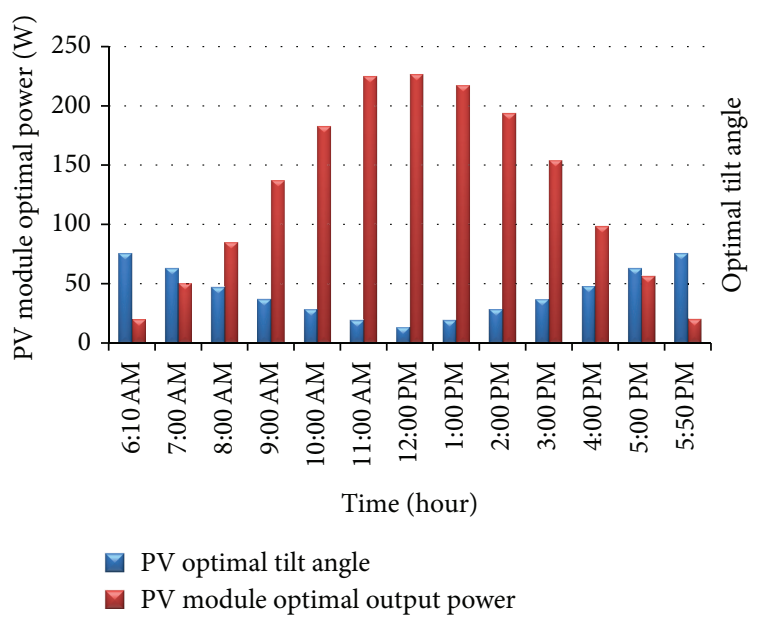

Figure 13: The optimal power and the corresponding tilt angle for June 10, 2012.

replace the solutions in the population that is selected for removal. The main elements of GA are populations of chromosomes, selection according to fitness, crossover to produce 
TABLE 2: Effect of changing the initial tilt angle on the module power at 6:10 AM.

\begin{tabular}{|c|c|c|c|c|c|c|c|c|}
\hline \multirow{2}{*}{$\begin{array}{l}\text { Initial solution } \\
{\left[\Sigma_{0}^{\circ}, \varphi_{c 0}^{\circ}, V_{0}^{M}\right]}\end{array}$} & \multicolumn{3}{|c|}{ Independent variables } & \multicolumn{3}{|c|}{ Dependant variables } & \multirow{2}{*}{$I^{M}(\mathrm{~A})$} & \multirow{2}{*}{$P_{\mathrm{pv}}(\mathrm{W})$} \\
\hline & $\Sigma^{\circ}$ & $\varphi_{C}^{\circ}$ & $V^{M}(\mathrm{~V})$ & $G_{C}\left(\mathrm{Kw} / \mathrm{m}^{2}\right)$ & $I_{0}(\mathrm{~A})$ & $T\left({ }^{\circ} \mathrm{C}\right)$ & & \\
\hline$\overline{U_{0}}=[0,5,30]$ & 56.5384 & 44.4320 & 43.4848 & 0.0887 & $4.5125 * 10^{-6}$ & 31.8929 & 0.4231 & 18.7692 \\
\hline$U_{0}=[3,5,30]$ & 51.2944 & 44.7359 & 43.4484 & 0.0877 & $4.4992 * 10^{-6}$ & 31.8609 & 0.4186 & 18.1864 \\
\hline$U_{0}=[6,5,30]$ & 54.6782 & 44.8905 & 43.3716 & 0.0887 & $4.5131 * 10^{-6}$ & 31.8944 & 0.4233 & 18.5889 \\
\hline$U_{0}=[9,5,30]$ & 58.7500 & 45.0000 & 43.4777 & 0.0915 & $4.5519 * 10^{-6}$ & 31.9871 & 0.4365 & 19.0712 \\
\hline$U_{0}=[12,5,30]$ & 63.5000 & 45.0000 & 43.5000 & 0.0932 & $4.5768 * 10^{-6}$ & 32.0463 & 0.4448 & 19.4612 \\
\hline$U_{0}=[15,5,30]$ & 49.6782 & 44.9171 & 43.3964 & 0.0843 & $4.4509 * 10^{-6}$ & 31.7443 & 0.4021 & 17.9730 \\
\hline$U_{0}=[18,5,30]$ & 49.2228 & 44.5000 & 43.3857 & 0.0833 & $4.4368 * 10^{-6}$ & 31.7098 & 0.3972 & 17.8469 \\
\hline$U_{0}=[21,5,30]$ & 56.2744 & 44.8397 & 43.2505 & 0.0887 & $4.5122 * 10^{-6}$ & 31.8921 & 0.4230 & 18.7031 \\
\hline$U_{0}=[24,5,30]$ & 47.3468 & 42.7325 & 43.4541 & 0.0816 & $4.4142 * 10^{-6}$ & 31.6547 & 0.3894 & 17.3567 \\
\hline$U_{0}=[27,5,30]$ & 51.5620 & 44.9079 & 43.2911 & 0.0862 & $4.4777 * 10^{-6}$ & 31.8091 & 0.4112 & 18.1797 \\
\hline$U_{0}=[30,5,30]$ & 67.2500 & 44.9020 & 43.4535 & 0.0941 & $4.5888 * 10^{-6}$ & 32.0746 & 0.4489 & 19.6382 \\
\hline$U_{0}=[33,5,30]$ & 73.7500 & 45.0000 & 43.4414 & 0.0956 & $4.6110 * 10^{-6}$ & 32.1269 & 0.4563 & 19.8390 \\
\hline$U_{0}=[36,5,30]$ & 74.7500 & 45.0000 & 43.4958 & 0.0957 & $4.6129 * 10^{-6}$ & 32.1313 & 0.4569 & 19.8724 \\
\hline$U_{0}=[39,5,30]$ & 75.7500 & 45.0000 & 43.4894 & 0.0957 & $4.6126 * 10^{-6}$ & 32.1307 & 0.4568 & 19.8726 \\
\hline$U_{0}=[42,5,30]$ & 76.0000 & 45.0000 & 43.3601 & 0.0953 & $4.6063 * 10^{-6}$ & 32.1160 & 0.4547 & 19.8134 \\
\hline $\mathrm{U}_{0}=[45,5,30]$ & 75.8125 & 45.0000 & 43.4999 & 0.0958 & $4.6131 * 10^{-6}$ & 32.1318 & 0.4570 & 19.8774 \\
\hline$U_{0}=[48,5,30]$ & 75.7500 & 45.0000 & 43.3796 & 0.0953 & $4.6069 * 10^{-6}$ & 32.1173 & 0.4549 & 19.8224 \\
\hline$U_{0}=[51,5,30]$ & 76.0000 & 45.0000 & 43.3997 & 0.0958 & $4.6130 * 10^{-6}$ & 32.1317 & 0.4569 & 19.8315 \\
\hline$U_{0}=[54,5,30]$ & 75.7500 & 45.0000 & 43.4689 & 0.0958 & $4.6131 * 10^{-6}$ & 32.1318 & 0.4569 & 19.8632 \\
\hline$U_{0}=[67,5,30]$ & 75.8125 & 45.0000 & 43.4989 & 0.0957 & $4.6129 * 10^{-6}$ & 32.1313 & 0.4569 & 19.8769 \\
\hline$U_{0}=[70,5,30]$ & 75.8125 & 45.0000 & 43.4903 & 0.0958 & $4.6131 * 10^{-6}$ & 32.1318 & 0.4570 & 19.8730 \\
\hline$U_{0}=[73,5,30]$ & 75.8125 & 45.0000 & 43.4989 & 0.0958 & $4.6131 * 10^{-6}$ & 32.1318 & 0.4570 & 19.8769 \\
\hline$U_{0}=[76,5,30]$ & 75.7500 & 45.0000 & 43.4963 & 0.0955 & $4.6099 * 10^{-6}$ & 32.1243 & 0.4559 & 19.8757 \\
\hline$U_{0}=[80,5,30]$ & 75.7813 & 45.0000 & 43.4966 & 0.0958 & $4.6130 * 10^{-6}$ & 32.1317 & 0.4569 & 19.8759 \\
\hline
\end{tabular}

new offspring, and random mutation of new offspring. A simple GA flow chart is shown in Figure 6.

The simplest form of genetic algorithm involves three types of operators: selection, crossover (single point), and mutation.

Selection. It selects chromosomes in the population for reproduction.

Crossover. It randomly chooses a locus and exchanges the subsequences before and after that locus between two chromosomes to create two offsprings.

Mutation. It randomly flips some of the bits in a chromosome.

3.3. The Method of Lagrange Multipliers. Lagrange multipliers, LM, play a vital role in the study of constrained optimization. It can be interpreted as the rate of change in the objective function with respect to changes in the associated constraint function [16]. The main formula of this method can be described as follows:

$$
\nabla_{U, X} f(U, X)=-\lambda \nabla_{U, X} g
$$

where $\nabla_{U, X} f=(\partial f / \partial U, \partial f / \partial X)$ and $\nabla_{U, X} g=(\partial g / \partial U, \partial g / \partial X)$ are the respective gradients. Constant $\lambda$ in (16) are called the Lagrange multipliers of the constrained problem.
By solving (15) one can get the value of $\lambda$ and then obtain the value of $U$ vector and $X$ vector at optimal solution and the optimal power extracted from the PV module. The proposed analysis uses a real data for solar radiation and ambient temperature measured by solar radiation and meteorological station located at National Research Institute of Astronomy and Geophysics Helwan, Cairo, Egypt, which is located at latitude $29.87^{\circ} \mathrm{N}$ and longitude $31.30^{\circ} \mathrm{E}$. The station is over a hill top of about $114 \mathrm{~m}$ height above sea level.

The initial condition of any optimization problem plays an important role in finding the optimal solution so GA program is performed under varying the initial condition of the independent variables until the optimal, maximum, power is obtained then Lagrange multiplier algorithm program is used and compared with GA to investigate the validity and quality of our proposed method.

The main steps of the proposed technique can be summarized as follows.

(1) Using the real data for solar radiation and ambient temperature as an input to genetic algorithm program that obtain the optimal output power from the PV module.

(2) Studying the effect of changing the initial population on the value of fitness function in order to obtain the optimal (maximum) possible power from the PV module. 
TABLE 3: Effect of changing the initial collector azimuth angle on the module power at 6:10 AM.

\begin{tabular}{|c|c|c|c|c|c|c|c|c|}
\hline \multirow{2}{*}{$\begin{array}{l}\text { Initial solution } \\
{\left[\Sigma_{0}^{\circ}, \varphi_{c 0}^{\circ}, V_{0}^{M}\right]} \\
\end{array}$} & \multicolumn{3}{|c|}{ Independent variables } & \multicolumn{3}{|c|}{ Dependant variables } & \multirow{2}{*}{$I^{M}(\mathrm{~A})$} & \multirow[b]{2}{*}{$P_{\mathrm{pv}}(\mathrm{W})$} \\
\hline & $\Sigma^{\circ}$ & $\varphi_{C}^{\circ}$ & $V^{M}(\mathrm{~V})$ & $G_{C}\left(\mathrm{Kw} / \mathrm{m}^{2}\right)$ & $I_{0}(\mathrm{~A})$ & $T\left({ }^{\circ} \mathrm{C}\right)$ & & \\
\hline$U_{0}=[45,-45,30]$ & 50.6146 & 44.5382 & 43.4679 & 0.0867 & $4.4841 * 10^{-6}$ & 31.8246 & 0.4134 & 18.0765 \\
\hline$U_{0}=[45,-40,30]$ & 53.9220 & 44.9146 & 43.3693 & 0.0880 & $4.5023 * 10^{-6}$ & 31.8683 & 0.4196 & 18.5043 \\
\hline$U_{0}=[45,-35,30]$ & 56.1325 & 44.2593 & 43.4265 & 0.0888 & $4.5140 * 10^{-6}$ & 31.8966 & 0.4236 & 18.6752 \\
\hline$U_{0}=[45,-30,30]$ & 55.7048 & 44.9776 & 43.3350 & 0.0874 & $4.4944 * 10^{-6}$ & 31.8495 & 0.4170 & 18.6999 \\
\hline$U_{0}=[45,-25,30]$ & 57.7381 & 44.7576 & 43.3907 & 0.0870 & $4.4883 * 10^{-6}$ & 31.8348 & 0.4149 & 18.8992 \\
\hline$U_{0}=[45,-20,30]$ & 53.4386 & 44.7737 & 43.2897 & 0.0877 & $4.4994 * 10^{-6}$ & 31.8615 & 0.4187 & 18.3925 \\
\hline$U_{0}=[45,-15,30]$ & 75.7500 & 44.9988 & 43.4602 & 0.0957 & $4.6130 * 10^{-6}$ & 32.1316 & 0.4569 & 19.8591 \\
\hline$U_{0}=[45,-10,30]$ & 75.7500 & 44.8301 & 43.4955 & 0.0956 & $4.6102 * 10^{-6}$ & 32.1250 & 0.4560 & 19.8452 \\
\hline$U_{0}=[45,-5,30]$ & 54.9162 & 44.5165 & 43.4248 & 0.0891 & $4.5189 * 10^{-6}$ & 31.9083 & 0.4253 & 18.5822 \\
\hline$U_{0}=[45,0,30]$ & 76.0000 & 44.7835 & 43.4785 & 0.0956 & $4.6104 * 10^{-6}$ & 32.1255 & 0.4561 & 19.8290 \\
\hline$U_{0}=[45,5,30]$ & 75.7500 & 45.0000 & 43.4714 & 0.0955 & $4.6100 * 10^{-6}$ & 32.1246 & 0.4559 & 19.8774 \\
\hline$U_{0}=[45,10,30]$ & 75.7500 & 45.0000 & 43.4771 & 0.0953 & $4.6062 * 10^{-6}$ & 32.1155 & 0.4547 & 19.8670 \\
\hline$U_{0}=[45,15,30]$ & 75.7500 & 45.0000 & 43.4837 & 0.0953 & $4.6069 * 10^{-6}$ & 32.1173 & 0.4549 & 19.8700 \\
\hline$U_{0}=[45,20,30]$ & 75.7500 & 45.0000 & 43.4731 & 0.0958 & $4.6131 * 10^{-6}$ & 32.1318 & 0.4570 & 19.8651 \\
\hline$U_{0}=[45,25,30]$ & 75.7500 & 45.0000 & 43.4553 & 0.0957 & $4.6122 * 10^{-6}$ & 32.1298 & 0.4567 & 19.8570 \\
\hline$U_{0}=[45,30,30]$ & 76.0000 & 45.0000 & 43.4579 & 0.0952 & $4.6052 * 10^{-6}$ & 32.1133 & 0.4543 & 19.8581 \\
\hline$U_{0}=[45,32,30]$ & 75.7500 & 45.0000 & 43.4983 & 0.0953 & $4.6068 * 10^{-6}$ & 32.1171 & 0.4549 & 19.8767 \\
\hline$U_{0}=[45,34,30]$ & 76.0000 & 45.0000 & 43.4766 & 0.0957 & $4.6124 * 10^{-6}$ & 32.1303 & 0.4567 & 19.8667 \\
\hline$U_{0}=[45,36,30]$ & 75.7500 & 45.0000 & 43.4935 & 0.0958 & $4.6130 * 10^{-6}$ & 32.1317 & 0.4569 & 19.8744 \\
\hline$U_{0}=[45,37,30]$ & 76.0000 & 45.0000 & 43.4558 & 0.0944 & $4.5943 * 10^{-6}$ & 32.0877 & 0.4507 & 19.8572 \\
\hline$U_{0}=[45,39,30]$ & 75.7500 & 45.0000 & 43.4837 & 0.0958 & $4.6130 * 10^{-6}$ & 32.1317 & 0.4569 & 19.8700 \\
\hline $\mathrm{U}_{0}=[45,41,30]$ & 75.7500 & 45.0000 & 43.4997 & 0.0957 & $4.6126 * 10^{-6}$ & 32.1307 & 0.4568 & 19.8776 \\
\hline$U_{0}=[45,43,30]$ & 75.7500 & 45.0000 & 43.4516 & 0.0957 & $4.6118 * 10^{-6}$ & 32.1289 & 0.4565 & 19.8553 \\
\hline$U_{0}=[45,45,30]$ & 75.7500 & 45.0000 & 43.4834 & 0.0953 & $4.6063 * 10^{-6}$ & 32.1160 & 0.4547 & 19.8698 \\
\hline
\end{tabular}

(3) The initial population at the optimal PV output power is fed to the Lagrange multiplier algorithm and comparing the results with those obtained by GA. Figure 7 shows these proposed technique steps.

\section{Numerical Analysis}

The analysis uses bpsx150 PV module which has 72 cells connected in series and its electrical characteristic is shown in Table 1 [17].

The bpsx150 PV module is simulated by MATLAB/ Simulink toolbox as shown in Figure 8. Referring to Figure 8, there are three main inputs which are the module voltage, the solar radiation, and the ambient temperature; these items are labeled in Figure 9 with numbers 1, 2, and 3. Simulink is a software package of MATLAB program for modeling, simulating, and analyzing dynamical systems. It supports linear and nonlinear systems, modeled in continuous time, sampled time, or a hybrid of the two. For modeling, Simulink provides a graphical user interface, GUI, for building models as block diagrams, using click and drag mouse operations. The detailed configuration of the PV module is given in Figure 9. The analysis of the proposed algorithm is performed on measured solar radiation and ambient temperature as inputs to GA program. These data are measured at Helwan city, for the sunny day of June 10, 2012, and start from
6:10 AM to 5:50 PM. The direct beam solar radiation and the corresponding ambient temperature, Helwan city, at latitude $29.87^{\circ}$, Egypt, are given in Figure 10.

The initial population of GA program which contains $\left(\Sigma_{0}, \varphi_{C 0}, V_{0}^{M}\right)$ plays an important role in finding the optimal power, so they are changed as follows.

(1) The initial tilt angle, $\Sigma_{0}$, is changed at acceptable limits, fixing both $\varphi_{\mathrm{C} 0}$ and $V_{0}^{M}$ at acceptable values until the maximum power is obtained as shown in Table 2.

The optimal output power for this case is equal to $19.8774 \mathrm{~W}$ at $\Sigma_{0}=45^{\circ}$ which is fixed at this value.

(2) Changing the initial PV module azimuth angle, $\varphi_{\mathrm{C} 0}$, at acceptable limits with fixed acceptable initial module voltage until the optimal power is obtained as shown in Table 3.

The optimal output power for this case is equal to $19.8776 \mathrm{~W}$ at $\varphi_{\mathrm{C} 0}=41$ which is fixed at this value.

(3) Changing the initial PV module voltage until the optimal power is obtained as shown in Table 4.

The final optimal output power is equal to $19.8778 \mathrm{~W}$ at $V_{0}^{M}=$ $42 \mathrm{~V}$. 
TABLE 4: Effect of changing the initial module voltage on the module power at 6:10 AM.

\begin{tabular}{|c|c|c|c|c|c|c|c|c|}
\hline \multirow{2}{*}{$\begin{array}{l}\text { Initial solution } \\
{\left[\Sigma_{0}^{\circ}, \varphi_{c 0}^{\circ}, V_{0}^{M}\right]} \\
\end{array}$} & \multicolumn{3}{|c|}{ Independent variables } & \multicolumn{3}{|c|}{ Dependant variables } & \multirow{2}{*}{$I^{M}(\mathrm{~A})$} & \multirow[b]{2}{*}{$P_{\mathrm{pv}}(\mathrm{W})$} \\
\hline & $\Sigma^{\circ}$ & $\varphi_{\mathrm{C}}^{\circ}$ & $V^{M}(\mathrm{~V})$ & $G_{C}\left(\mathrm{Kw} / \mathrm{m}^{2}\right)$ & $I_{0}(\mathrm{~A})$ & $T\left({ }^{\circ} \mathrm{C}\right)$ & & \\
\hline$\overline{U_{0}=[45,41,0]}$ & 51.8224 & 44.5636 & 43.3348 & 0.0872 & $4.4921 * 10^{-6}$ & 31.8439 & 0.4162 & 18.1819 \\
\hline$U_{0}=[45,41,2]$ & 56.3961 & 45.0000 & 43.4018 & 0.0899 & $4.5301 * 10^{-6}$ & 31.9350 & 0.4291 & 18.8057 \\
\hline$U_{0}=[45,41,4]$ & 76.0000 & 44.9427 & 43.2811 & 0.0957 & $4.6123 * 10^{-6}$ & 32.1299 & 0.4567 & 19.7672 \\
\hline$U_{0}=[45,41,6]$ & 53.7614 & 44.8565 & 43.4569 & 0.0859 & $4.4740 * 10^{-6}$ & 31.8003 & 0.4100 & 18.5142 \\
\hline$U_{0}=[45,41,8]$ & 54.9695 & 44.5616 & 43.4382 & 0.0889 & $4.5158 * 10^{-6}$ & 31.9008 & 0.4242 & 18.6007 \\
\hline$U_{0}=[45,41,10]$ & 76.0000 & 45.0000 & 43.3597 & 0.0958 & $4.6131 * 10^{-6}$ & 32.1318 & 0.4570 & 19.8132 \\
\hline$U_{0}=[45,41,12]$ & 53.1965 & 44.7522 & 43.4134 & 0.0875 & $4.4960 * 10^{-6}$ & 31.8533 & 0.4175 & 18.4128 \\
\hline$U_{0}=[45,41,14]$ & 76.0000 & 44.9767 & 43.3995 & 0.0957 & $4.6127 * 10^{-6}$ & 32.1308 & 0.4568 & 19.8273 \\
\hline$U_{0}=[45,41,16]$ & 75.7500 & 45.0000 & 43.4834 & 0.0957 & $4.6129 * 10^{-6}$ & 32.1313 & 0.4569 & 19.8698 \\
\hline$U_{0}=[45,41,18]$ & 75.8750 & 45.0000 & 43.4408 & 0.0949 & $4.6006 * 10^{-6}$ & 32.1023 & 0.4528 & 19.8504 \\
\hline$U_{0}=[45,41,20]$ & 75.7500 & 45.0000 & 43.4871 & 0.0958 & $4.6131 * 10^{-6}$ & 32.1318 & 0.4570 & 19.8716 \\
\hline$U_{0}=[45,41,22]$ & 76.0000 & 45.0000 & 43.4579 & 0.0958 & $4.6131 * 10^{-6}$ & 32.1318 & 0.4569 & 19.8581 \\
\hline$U_{0}=[45,41,24]$ & 75.7500 & 45.0000 & 43.4499 & 0.0955 & $4.6092 * 10^{-6}$ & 32.1227 & 0.4557 & 19.8545 \\
\hline$U_{0}=[45,41,26]$ & 75.7500 & 45.0000 & 43.4741 & 0.0949 & $4.6003 * 10^{-6}$ & 32.1017 & 0.4527 & 19.8728 \\
\hline$U_{0}=[45,41,28]$ & 75.7500 & 45.0000 & 43.4839 & 0.0958 & $4.6131 * 10^{-6}$ & 32.1318 & 0.4569 & 19.8701 \\
\hline$U_{0}=[45,41,30]$ & 76.0000 & 45.0000 & 43.4818 & 0.0958 & $4.6130 * 10^{-6}$ & 32.1316 & 0.4569 & 19.8776 \\
\hline$U_{0}=[45,41,32]$ & 75.7500 & 45.0000 & 43.4565 & 0.0956 & $4.6115 * 10^{-6}$ & 32.1281 & 0.4564 & 19.8575 \\
\hline$U_{0}=[45,41,34]$ & 75.7500 & 45.0000 & 43.4324 & 0.0957 & $4.6129 * 10^{-6}$ & 32.1313 & 0.4569 & 19.8466 \\
\hline$U_{0}=[45,41,36]$ & 75.6875 & 45.0000 & 43.4969 & 0.0958 & $4.6131 * 10^{-6}$ & 32.1318 & 0.4570 & 19.8760 \\
\hline$U_{0}=[45,41,38]$ & 75.7500 & 45.0000 & 43.4403 & 0.0958 & $4.6130 * 10^{-6}$ & 32.1317 & 0.4569 & 19.8501 \\
\hline$U_{0}=[45,41,40]$ & 75.7500 & 45.0000 & 43.4393 & 0.0958 & $4.6131 * 10^{-6}$ & 32.1318 & 0.4569 & 19.8497 \\
\hline $\mathrm{U}_{0}=[45,41,42]$ & 76.0000 & 45.0000 & 43.5000 & 0.0957 & $4.6129 * 10^{-6}$ & 32.1315 & 0.4569 & 19.8778 \\
\hline$U_{0}=[45,41,43]$ & 75.5625 & 45.0000 & 43.4655 & 0.0955 & $4.6098 * 10^{-6}$ & 32.1241 & 0.4559 & 19.8615 \\
\hline$U_{0}=[45,41,43.5]$ & 75.5000 & 45.0000 & 43.5000 & 0.0958 & $4.6130 * 10^{-6}$ & 32.1317 & 0.4564 & 19.8772 \\
\hline
\end{tabular}

TABLE 5: The optimal power and the corresponding tilt angle by GA for June 10, 2012.

\begin{tabular}{lccc}
\hline Hour & $\begin{array}{c}\text { Initial condition at } \\
\text { optimal solution } \\
{\left[\Sigma_{0}, \varphi_{c 0}, V_{0}^{M}\right]}\end{array}$ & $\begin{array}{c}\text { Tilt angle at } \\
\text { optimal power }\end{array}$ & $\begin{array}{c}\text { Optimal } \\
\text { power }(\mathrm{W})\end{array}$ \\
\hline 6:10 AM & {$[45,41,42]$} & 75.7500 & 19.8773 \\
7:00 AM & {$[54,32,26]$} & 63.4998 & 50.0546 \\
8:00 AM & {$[27,30,42]$} & 47.2500 & 84.8483 \\
9:00 AM & {$[42,36,14]$} & 36.9459 & 137.1025 \\
10:00 AM & {$[21,32,42]$} & 28.2500 & 182.8460 \\
11:00 AM & {$[70,0,36]$} & 19.2309 & 225.0597 \\
12:00 PM & {$[18,30,42]$} & 13.0219 & 226.6207 \\
1:00 PM & {$[30,10,43.5]$} & 19.3121 & 217.1806 \\
2:00 PM & {$[54,30,43.5]$} & 28.2298 & 194.0017 \\
3:00 PM & {$[3,5,32]$} & 36.7493 & 153.7899 \\
4:00 PM & {$[73,-40,43.5]$} & 47.7500 & 98.8123 \\
5:00 PM & {$[24,-35,43.5]$} & 63.5000 & 56.5923 \\
5:50 PM & {$[70,-45,16]$} & 75.8125 & 20.2942 \\
\hline
\end{tabular}

Finally, one can derive that the optimal obtained power by GA at 6:10 AM is equal to $19.8778 \mathrm{~W}$ and is occurred at initial population which is equal to $\left(\Sigma_{0}^{\circ}, \varphi_{C 0}^{\circ}, V_{0}^{M}\right)=\left(45^{\circ}, 41^{\circ}, 42 \mathrm{~V}\right)$. The curve shows the change of PV module power with changing the initial population is shown in Figure 11. GA program response is shown in Figure 12 that contains the fitness function, the current best individuals, the average distance between individuals and the number of individuals for each iteration. The constant dependant values at optimal power are $\delta=17.5165, \beta=10.7181, m=5.3770, \varphi_{S}=$ 75.8452 , and $\omega=60$.

The final population at optimal solution is equal to $\Sigma=$ $75.7500, \varphi_{C}=45.0000$, and $V^{M}=43.5000$.

The optimal power and the corresponding tilt angle for 24 hours of the day are shown in Figure 13 and Table 5.

Once the bpsx150 PV module has a fixed number of series cells, $N_{S}=72$, and a fixed number of parallel branches, $N_{P}=$ 1 , then they are not be considered as variables.

The initial condition at optimal power obtained from the GA is fed to the Lagrange multiplier algorithm to find the optimal power. The MATLAB function fmincon is used to perform the Lagrange multiplier analysis.

The Lagrange multiplier algorithm response is shown in Figure 14. A comparison between the GA and Lagrange multiplier algorithm is performed and is shown in Figure 15 and Table 6.

A comparison between the GA and Lagrange multiplier algorithm is performed and is shown in Figure 14 and Table 6.

It is clear that the difference between two proposed solution methods is very small as the initial condition of them is the same; the operating conditions of the PV module do 
TABLE 6: A comparison between the GA and Lagrange multiplier algorithm.

\begin{tabular}{|c|c|c|c|c|c|c|}
\hline \multirow{2}{*}{ Hour } & \multicolumn{2}{|c|}{ Genetic algorithm solution } & \multicolumn{2}{|c|}{ Lagrange multiplier algorithm results } & \multirow{2}{*}{$\begin{array}{c}\text { Error in optimal tilt } \\
\text { angle }\end{array}$} & \multirow{2}{*}{$\begin{array}{c}\text { Error in optimal } \\
\text { power }\end{array}$} \\
\hline & $\Sigma_{\text {opt }}$ & $P_{\text {opt }}$ & $\Sigma_{\text {opt }}$ & $P_{\text {opt }}$ & & \\
\hline 6:10 AM & 75.7500 & 19.8773 & 75.8114 & 19.8774 & -0.0614 & $-1 E-04$ \\
\hline 7:00 AM & 63.4998 & 50.0546 & 63.4993 & 50.0486 & 0.0005 & 0.006 \\
\hline 8:00 AM & 47.2500 & 84.8483 & 47.3668 & 84.8485 & -0.1168 & -0.0002 \\
\hline 9:00 AM & 36.9459 & 137.1025 & 36.8401 & 137.1174 & 0.1058 & -0.0149 \\
\hline 10:00 AM & 28.2500 & 182.8460 & 28.2483 & 182.8456 & 0.0017 & 0.0004 \\
\hline 11:00 AM & 19.2309 & 225.0597 & 19.2598 & 225.0807 & -0.0289 & -0.021 \\
\hline 12:00 PM & 13.0219 & 226.6207 & 13.0221 & 226.6537 & -0.0002 & -0.033 \\
\hline 1:00 PM & 19.3121 & 217.1806 & 19.2598 & 217.1956 & 0.0523 & -0.015 \\
\hline 2:00 PM & 28.2298 & 194.0017 & 28.2483 & 194.0071 & -0.0185 & -0.0054 \\
\hline 3:00 PM & 36.7493 & 153.7899 & 36.8401 & 153.8525 & -0.0908 & -0.0626 \\
\hline 4:00 PM & 47.7500 & 98.8123 & 47.3668 & 98.8142 & 0.3832 & -0.0019 \\
\hline 5:00 PM & 63.5000 & 56.5923 & 63.4993 & 56.5563 & 0.0007 & 0.036 \\
\hline 5:50 PM & 75.8125 & 20.2942 & 75.8114 & 20.2752 & 0.0011 & 0.019 \\
\hline
\end{tabular}

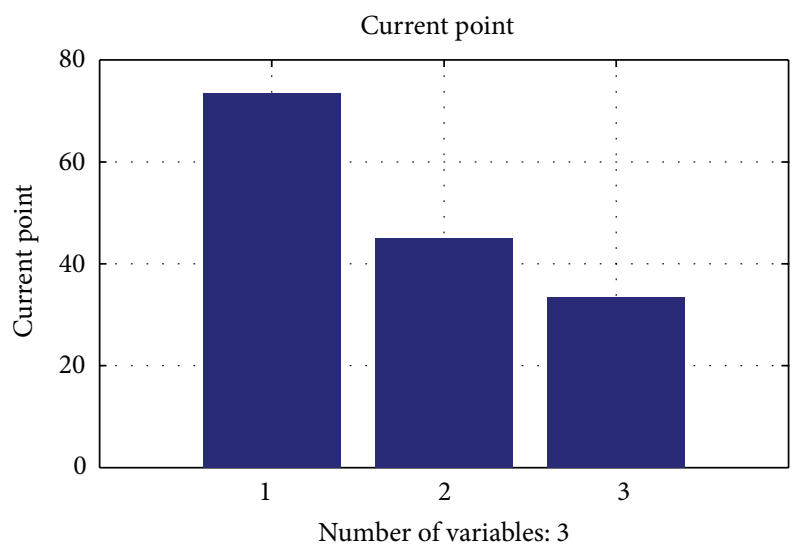

(a)

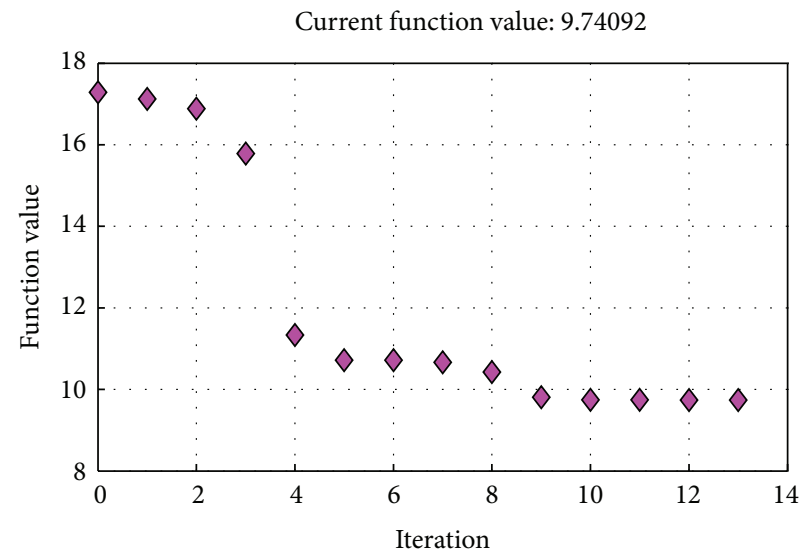

(b)

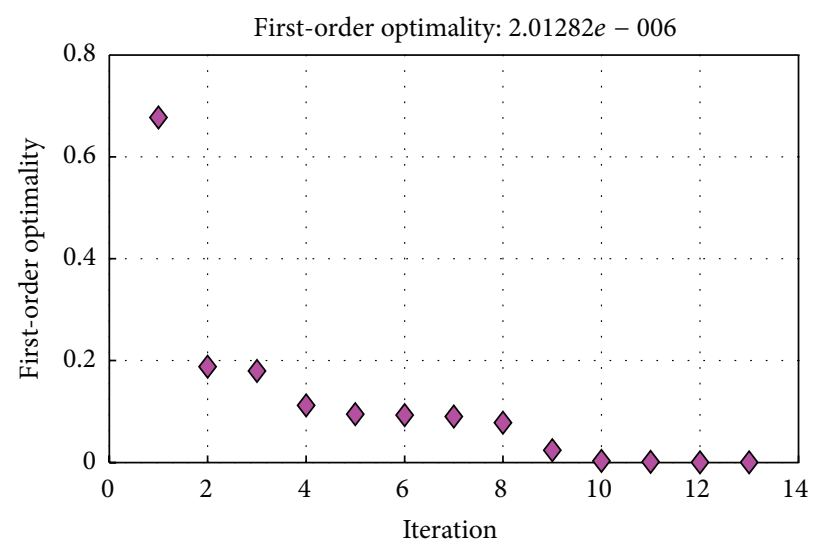

(c)

FIGURE 14: The Lagrange multiplier response.

not change. So, one can derive that the error between two methods is acceptable and the proposed method is applicable.

The benefits of this proposed approach are as follows.

(i) A new objective function of the PV module output power subjected to constraints is presented. (ii) A simple optimization methodology to obtain the optimal power extracted from the PV module and corresponding tilt angle based on real data is formulated.

(iii) Two suggested solution techniques are manipulated and the error between them is very small. 


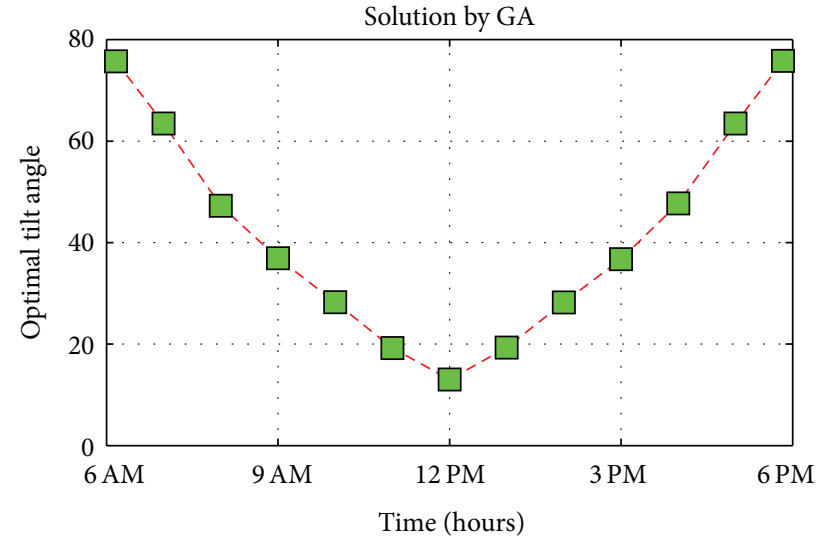

(a)

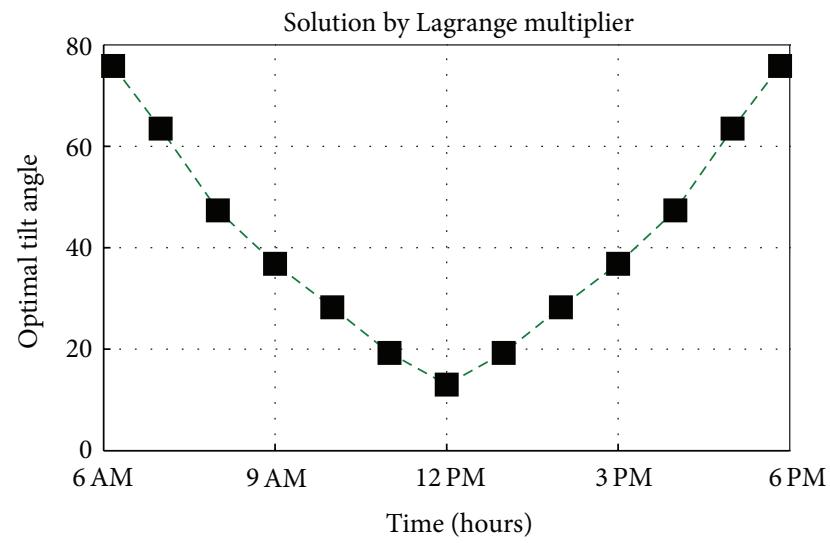

(c)

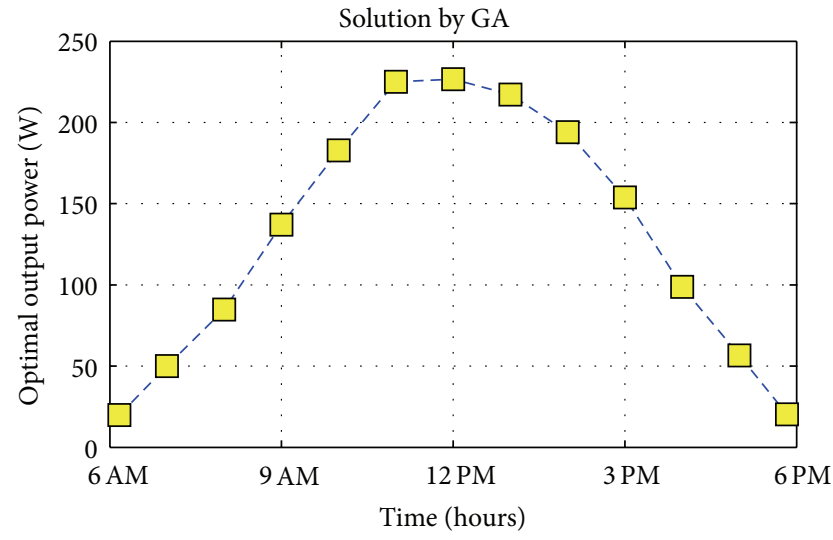

(b)

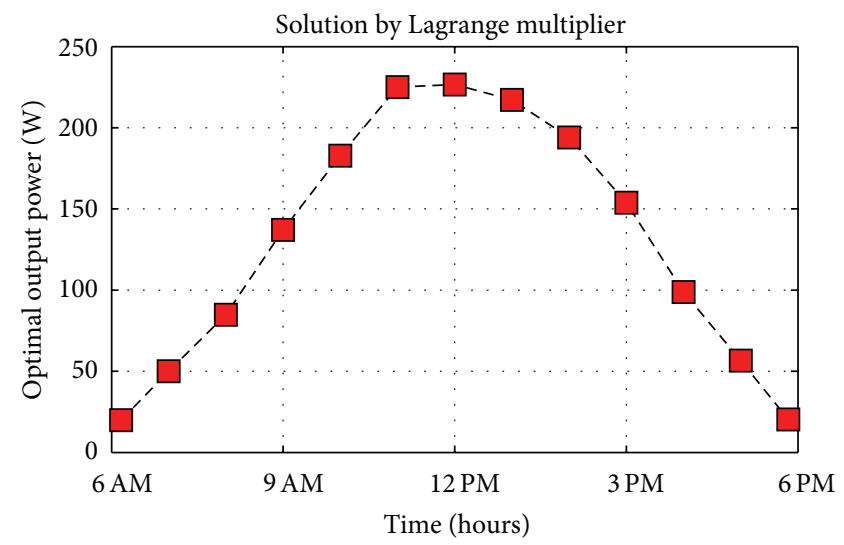

(d)

FIGURE 15: A comparison between the GA and Lagrange multiplier algorithm responses.

\section{Conclusion}

In this work a new optimization approach to maximize the PV module output power is presented. A new proposed objective function of PV module power and constraints is also presented. Genetic algorithm is performed under varying the initial population of independent variables, then Lagrange multiplier algorithm is simulated. The optimal PV module power obtained from both algorithms is compared. The analysis is based on real measured data of solar radiation and ambient temperature at Helwan city at latitude $29.87^{\circ}$, Egypt. The analysis is done in complete sunny day and the results showed that the error between two proposed solution techniques is acceptable and the proposed constrained optimization method is applicable.

\section{Acknowledgment}

Cordial thanks and deep respect are offered to the Solar and Space Research Department, National Research Institute of Astronomy and Geophysics, Helwan, Egypt, for supporting this work and providing the authors with the required real data.

\section{References}

[1] G. M. Masters, Renewable and Efficient Electric Power Systems, John Wiley \& Sons, Hoboken, NJ, USA, 2004.

[2] C. Liu, B. Wu, and R. Cheung, "Advanced algorithm for MPPT control of photovoltaic systems," in Proceedings of the Canadian Solar Buildings Conference, Montreal, Canada, 2004.

[3] M. Farhat and L. Sbita, "Advanced fuzzy MPPT control algorithm for photovoltaic systems," Science Academy Transactions on Renewable Energy Systems Engineering and Technology, vol. 1, no. 1, 2011.

[4] B. Amrouche, M. Belhamel, and A. Guessoum, "Artificial intelligence based P\&O MPPT method for photovoltaic systems," Review of Renewable Energy ICRESD-07 Tlemcen, pp. 11-16, 2007.

[5] C. S. Chin, P. Neelakantan, H. P. Yoong, and K. T. K. Teo, "Optimisation of fuzzy based maximum power point tracking in PV system for rapidly changing solar irradiance," Transaction on Solar Energy and Planning, vol. 2, 2011.

[6] G. Zeng, X. Zhang, J. Ying, and C. Ji, "A novel intelligent fuzzy controller for MPPT in grid-connected photovoltaic systems," in Proceedings of the 5th WSEAS/IASME International Conference on Electric Power Systems, High Voltages, Electric Machines, pp. 515-519, Tenerife, Spain, 2005. 
[7] M. S. Aït Cheikh, C. Larbes, G. F. Tchoketch Kebir, and A. Zerguerras, "Maximum power point tracking using a fuzzy logic control scheme," Revue Des Energies Renouvelables, vol. 10, no. 3, pp. 387-395, 2007.

[8] P. Takun, S. Kaitwanidvilai, and C. Jettanasen, "Maximum power point tracking using fuzzy logic control for photovoltaic systems," in Proceedings of the International Multi Conference of Engineers and Computer Scientists (IMECS '11), vol. 2, pp. 986990, March 2011.

[9] M. El Ouariachi, T. Mrabti, M. F. Yaden, K. Kassmi, and K. Kassmi, "Analysis, optimization and modeling of electrical energies produced by the photovoltaic panels and systems," Revue Des Energies Renouvelables, vol. 14, no. 4, pp. 707-716, 2011.

[10] K. Ishaque, Z. Salam, A. Shamsudin, and M. Amjad, "A direct control based maximum power point tracking method for photovoltaic system under partial shading conditions using particle swarm optimization algorithm," Applied Energy Journal, vol. 99, pp. 414-422, 2012.

[11] T. Perpétuo Corrêa, S. Isaac Seleme Jr., and S. Rocha Silva, "Efficiency optimization in stand-alone photovoltaic pumping system," Renewable Energy Journal, vol. 41, pp. 220-226, 2012.

[12] G. M. Masters, Renewable and Efficient Electric Power Systems, John Wiley \& Sons, Hoboken, NJ, USA, 2004.

[13] N. Hidouri and L. sbita, "Water photovoltaic pumping system based on DTC SPMSM drives," Journal of Electric Engineering, vol. 1, no. 2, pp. 111-119, 2010.

[14] B. Krishna Kumar, "Matlab based modelling of photovoltaic panels and their efficient, utilization for maximum power generation," in Proceedings of the 1st National Conference on Intelligent Electrical Systems (NCIES '09), pp. 125-130, Salem, India, 2009.

[15] A. M. Othman, M. M. M. El-Arini, A. Ghitas, and A. Fathy, "Realworld maximum power point tracking simulation of PV system based on fuzzy logic control," in Proceedings of the $3 \mathrm{rd}$ Arab Conference on Astronomy and Geophysics ( ACAG '12), Helwan, Cairo, Egypt, 2012.

[16] Z. Michalewicz, Genetic Algorithms + Data Structures = Evolution Programs, Springer, New York, NY, USA, 2nd edition, 1994.

[17] http://abcsolar.com/pdf/bpsx150.pdf. 

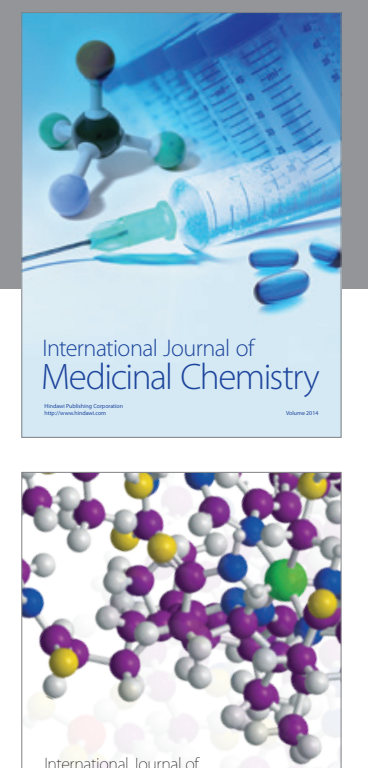

\section{Carbohydrate} Chemistry

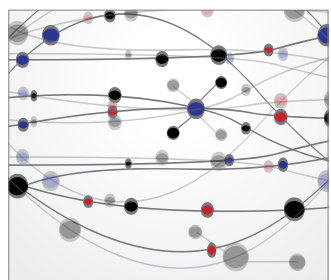

The Scientific World Journal
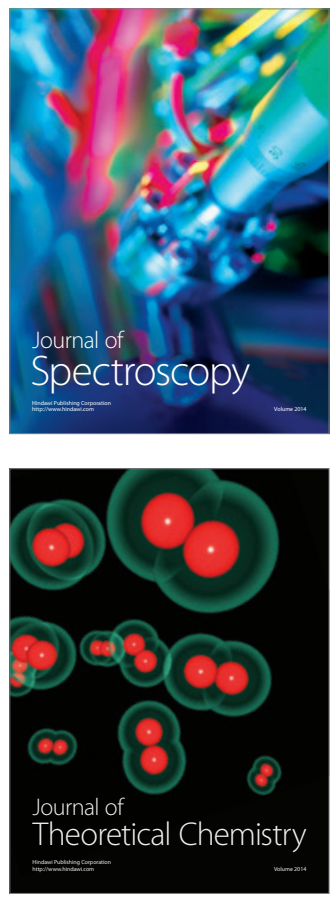
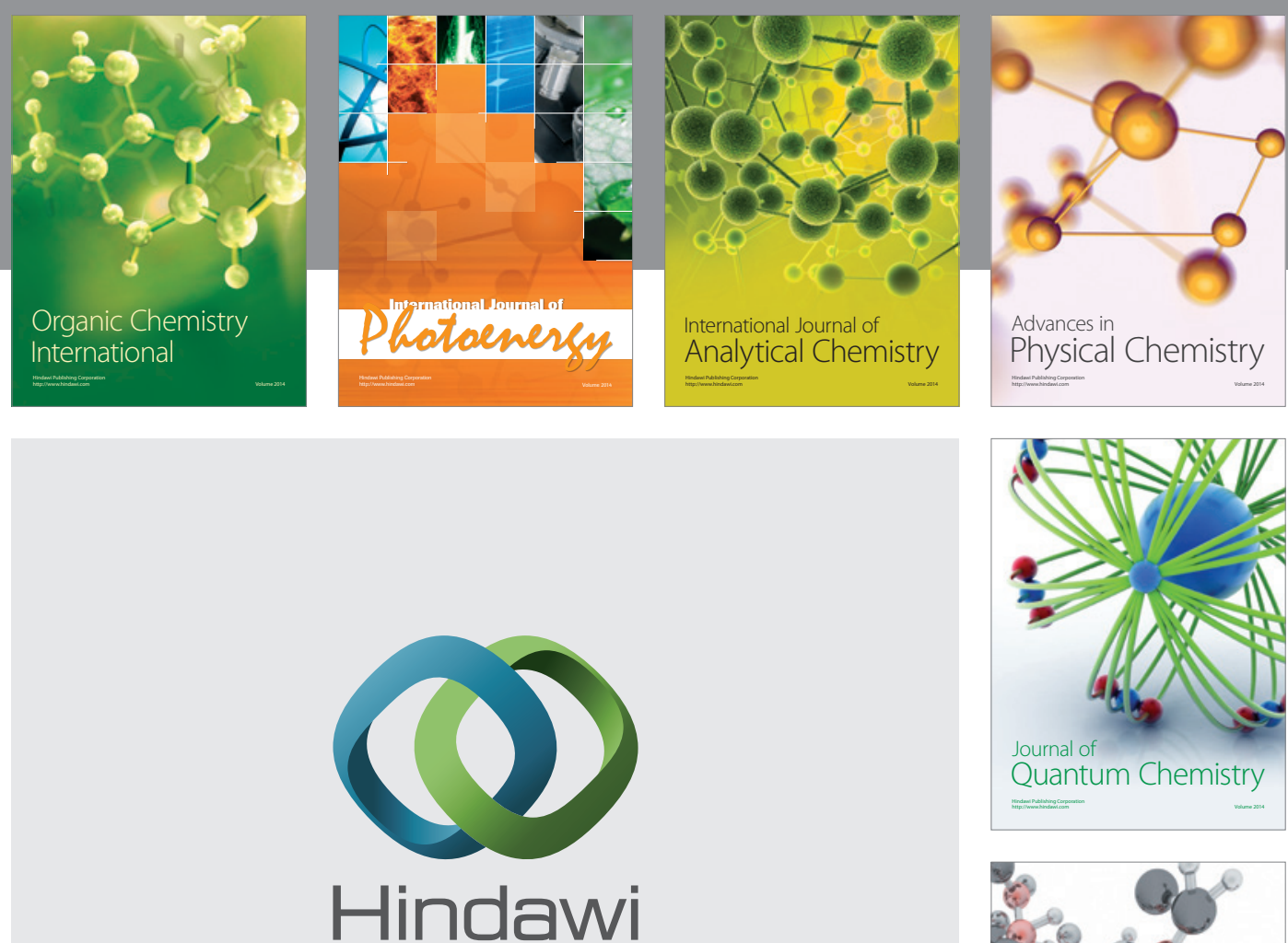

Submit your manuscripts at

http://www.hindawi.com

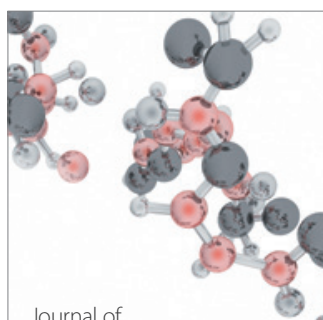

Analytical Methods

in Chemistry

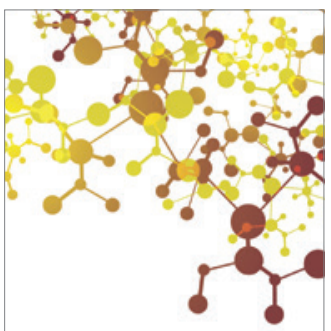

Journal of

Applied Chemistry

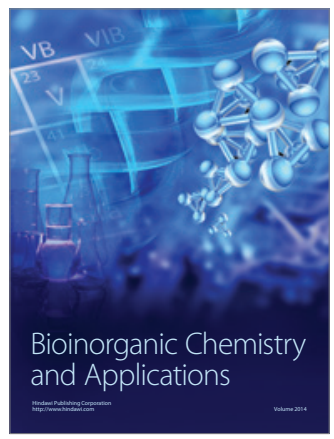

Inorganic Chemistry
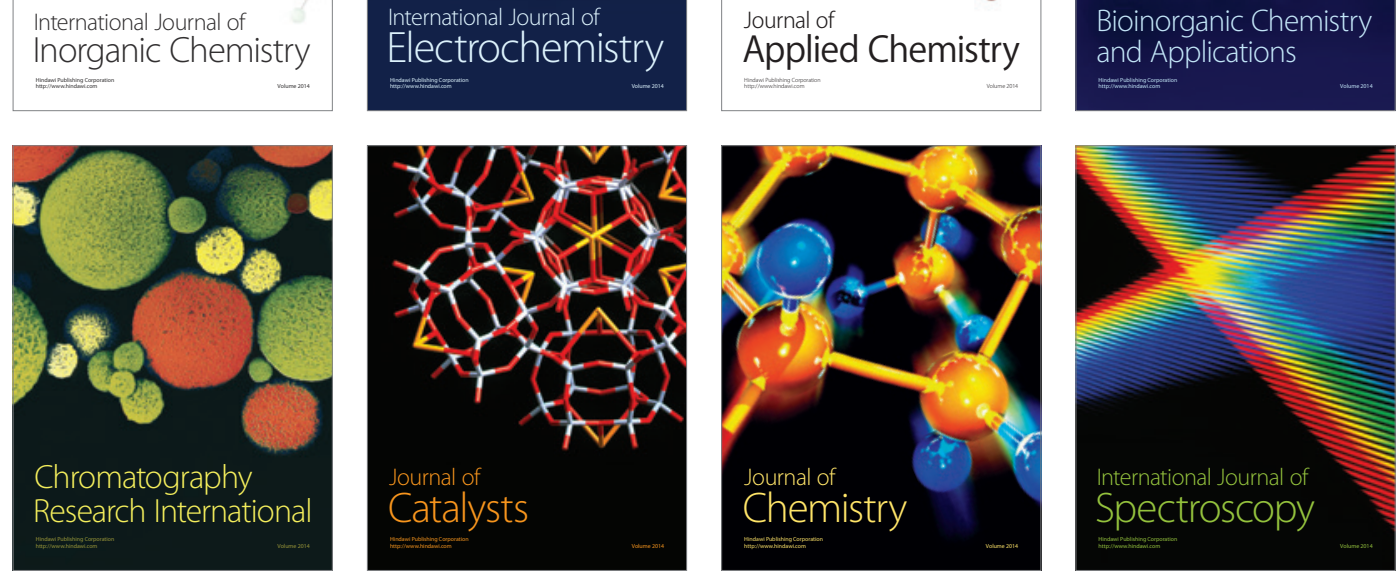